\title{
RECONFIGURAÇÃO DO ENSINO SUPERIOR BRASILEIRO: DIREITO OU DESMONTE?
}

\begin{tabular}{c}
\hline RECONFIGURATION OF BRAZILIAN HIGNER EDUCATION: \\
RIGHT OR DISMOUNT? \\
\hline RECONFIGURACIÓN DE LA EDUCACIÓN SUPERIOR BRASILEÑA: \\
¿DERECHO O DESMONTE?
\end{tabular}

Maria Luciene da Silva Araújo ${ }^{\prime}$

RESUMO: A democratização do acesso à Educação Superior no Brasil, atualmente, pauta-se em políticas que prezam pela mercantilização e precarização deste nível de ensino. Destarte, este artigo objetiva discutir elementos históricos da Educação Superior brasileira e da Assistência Estudantil, analisando as formas que as(os) estudantes ingressam nas universidades brasileiras, tendo em vista a formulação e implementação de políticas voltadas para o acesso e a permanência no meio acadêmico. Conforme revisão de literatura, é possível apreender que o Estado brasileiro mantém subserviência aos ditames do capital internacional, o que se faz sentir nas ações governamentais destinadas para a educação, em especial a educação superior. Destarte, ao problematizar tal temática é possível afirmar que, as políticas de democratização de acesso as universidades devem ser providas pela primazia do Estado, bem como devem ser articuladas com políticas de Assistência Estudantil, compondo um conjunto de ações estatais direcionadas para a garantia da permanência de sujeitos historicamente marginalizados, assegurando uma educação de qualidade, pública e para todas(os).

PALAVRAS-CHAVE: Educação superior. Assistência estudantil. Democratização.

ABSTRACT: The democratization of access to Higher Education in Brazil today is based on policies that value the commodification and precariousness of this level of education. This article aims to discuss historical elements of Brazilian Higher Education and Student Assistance, analyzing the ways students enter Brazilian universities, in accordance formulate and implement policies aimed at access and stay in the academic environment. According to literature review, it is possible to perceive that the Brazilian state maintains subservience to the dictates of international capital, which is done government actions aimed at education, especially Higher Education. Thus, in problematizing such a theme, it is possible to affirm that the democratization policies of access to universities should be provided by the primacy of the State, as well as should be articulated with Student Assistance policies, comprising a set of state actions aimed at guaranty the of permanence of historically marginalized subjects, ensuring a quality education, public and for all.

KEYWORDS: Higher education. Student assistance. Democratization.

RESUMEN: La democratización del acceso a la Educación Superior en Brasil, actualmente, se pauta en políticas que precan por la mercantilización y precarización de este nivel de enseñanza. De este modo, este artículo objetiva discutir elementos históricos de la Educación Superior brasileña y de la Asistencia Estudiantil, analizando las formas que las (los) estudiantes ingresan en las universidades brasileñas, teniendo en vista la formulación e implementación de políticas dirigidas al acceso y la permanencia en el medio académico. Conforme a la revisión de literatura, es posible aprehender que el Estado brasileño mantiene la subordinación a los dictámenes del capital internacional, lo que se hace En las acciones gubernamentales destinadas a la

Submetido em: 20/06/2017 - Aceito em: 18/07/2017 - Publicado em: 06/09/2017.

\begin{tabular}{|l|c|c|c|c|c|} 
(C) Rev. Inter. Educ. Sup. & Campinas, SP & v.3 & n.3 & $645-677$ & set./dez. 2017 \\
\hline
\end{tabular}


educación, en particular la Educación Superior. Por lo tanto, al problematizar tal temática es posible afirmar que las políticas de democratización de acceso a las universidades deben ser de providencias por la primacía del Estado, así como deben ser articuladas con políticas de Asistencia Estudiantil, componiendo un conjunto de acciones estatales dirigidas a la garantía de la garantía permanencia de sujetos históricamente marginados, asegurando una educación de calidad, pública y para todas (os).

PALABRAS ClAVE: Educación superior. Asistencia estudiantil. Democratización.

\section{INTRODUÇÃo}

No Brasil, as políticas educacionais, a partir da década de 1990, foram formuladas para o atendimento de uma aprendizagem mínima, cujos critérios encontravam-se fincados no quesito renda (LIBÂNEO, 2012), com ações focalizadas para o aumento do índice de escolaridade, a superação da pobreza, acirrando as desigualdades sociais e modelando a(o) estudante para o atendimento ao mercado. Uma educação direcionada para atender as orientações do Banco Mundial (BM), almejando o desenvolvimento dos países periféricos (ANDRADE, 2012).

O que refere-se a consolidação da Educação Superior brasileira, esta deteve dois pontos de arranque: de um lado, a necessidade de mão de obra qualificada para atuar no país em desenvolvimento, de outro, a pressão exercida pela classe trabalhadora para ter acesso ao saber científico (DAHMER, 2007). Este fato esteve calcado em uma base histórica a qual as classes populares estavam relegadas a conter-se com o ensino profissionalizante (MOURA, 2007), enquanto a classe abastada ocupava os bancos universitários, caracterizando, assim, a universidade brasileira de burguesa, seletiva e excludente.

Diante deste cenário educacional, os governantes Lula da Silva (2002-2009) e Dilma Rousseff (2010-2015), ambos integrantes do Partido dos Trabalhadores (PT), empenharam-se na formulação de políticas que primassem pela inclusão dos sujeitos, historicamente marginalizados, nas Instituições de Ensino Superior (IES's), visando reverter este quadro da Educação Superior. Contudo, é válido frisar que, estas ações, empenhadas nestes governos, não apenas avançam na expansão do ensino superior, mas instituem a garantia inversa ao campo do direito, uma vez que a democratização do ensino é efetivada por intermédio de programas que financiam a esfera privada.

Destarte, o acesso as universidades públicas brasileiras ainda constitui-se um privilégio de algumas(ns), seja pelas limitadas vagas ofertadas no setor público, seja pela condição financeira de arcar com as despesas e as dificuldades de permanência nas IES's, o que nos leva a pontuar duas questões pertinentes para o debate da formação profissional, de nível superior, em nosso país: o acesso à universidade e a permanência neste espaço. Tais questões

\begin{tabular}{l|l|l|l|l|l|} 
(ㅇ) Rev. Inter. Educ. Sup. & Campinas, SP & v.3 & n.3 & $645-677$ & set./dez. 2017 \\
\hline
\end{tabular}


requerem uma discussão articulada a história da universidade na sociedade brasileira, bem como o reconhecimento dos limites e potencialidades das políticas voltadas para cada uma delas.

Desse modo, estudaremos o histórico da política de Educação Superior no Brasil, a fim de discutirmos a reconfiguração da mesma, apontando a importância da política de Assistência Estudantil para a democratização das universidades. Salienta-se que, esta política encontra-se no dilema de assegurar a permanência de estudantes das classes populares, enquanto a democratização do ensino superior ocorre de forma a provocar o desmonte da política pública de educação.

O referido desmonte da política de educação superior é mediado por uma expansão e democratização que se materializa por iniciativas que mercantilizam e precarizam o ensino, tais como o Fundo de Financiamento Estudantil (FIES), o Programa Universidade para Todos (PROUNI) e a Educação a Distância (EaD), constituindo uma "democratização que revela uma crescente privatização, o aumento do sucateamento e a precarização do ensino público" (ARAÚJO; LEITE, 2016, p. 05), descaracterizando o direito estabelecido pela Carta Magna de 1988, que dispõe sobre a sua gratuidade, universalidade e qualidade.

\section{APONTAMENTOS HISTÓRICOS}

A formação da sociedade brasileira, no período colonial, não contou com a preocupação de desenvolver um ensino superior para seus habitantes, logo os sujeitos que desejavam ingressar na academia precisavam morar na Europa (OLIVE, 2002). Este fato, segundo Silva (2014), levou Anísio Teixeira a consagrar a Universidade de Coimbra como a primeira universidade brasileira, tendo em vista que os filhos dos colonos brasileiros tinham acesso a este nível de ensino nesta instituição.

Infere-se que, este desinteresse pela Educação Superior deriva da resistência da Coroa portuguesa, por tratar-se de uma ameaça ao seu poder centralizador na colônia brasileira, haja vista a preeminente chance de desvinculação política e cultural da mesma (FÁVERO, 2006; SILVA, 2014). No entanto, é válido destacar as significativas mudanças na oferta da educação no período colonial, sendo a de maior impacto, para a sociedade brasileira, ocorrida em 1808, quando, em decorrência do governo de Napoleão Bonaparte, a Família Real encontrou-se obrigada a refugiar-se em sua colônia latino-americana (SILVA 2014).

Com a chegada da Corte Portuguesa, a então capital do Brasil, Rio de Janeiro, foi alvo de inúmeras transformações sociais, econômicas e políticas para atender os requisitos e anseios 
da Corte, os quais demandavam mão de obra qualificada para impulsionar o desenvolvimento da colônia. Assim, dentre as transformações ocorridas, temos o desenvolvimento do ensino na região, com cursos de nível médio, superior e militares, para atender as demandas da aristocracia (ROCHA, 2010),

Em 1822, Dom Pedro I proclama a Independência da colônia à Corte. Esta mudança no cenário político impulsionou o caráter de urgência da instrução popular, tendo em vista que uma massa populacional leiga significava obstáculo para os "princípios liberais e democráticos que, associados ao movimento da independência, fundamentavam o novo regime [...]" (PERES, 2010, p. 48). Desta feita, O projeto educacional, que se gestava nos marcos da constituinte, tratou "o ensino superior e a educação popular [...] como estruturas paralelas, refletindo preocupações e interesses distintos: de um lado, a formação de elite; de outro, a educação popular" (Ibidem), consolidando a elitização do ensino elevado.

No que refere-se a Educação Superior, em seus primórdios no contexto brasileiro, foram gestadas as formações profissionais voltadas para atender a Família Real, sendo o primeiro curso de Cirurgia, Anatomia e Obstetrícia (1808), em Salvador. Logo após, tivemos as Academias Militares (1808 e 1810), no Rio de Janeiro, "sendo instituída a Academia Real Militar, onde foi implantado o núcleo que deu início à Escola de Engenharia da Universidade Federal do Rio de Janeiro" (SILVA, 2014, p. 18).

Contudo, não configuravam-se como universidades, havendo a promessa de criação das mesmas no ato da Proclamação da República, em 1889. Entretanto, somente em 1920, por meio do decreto 14. 343/1920, o então Presidente da República, Epitácio Pessoa, com base na reforma ocorrida em 1915, conhecida como a Reforma Carlos Maximiliano ${ }^{2}$, instala a Universidade do Rio de Janeiro ${ }^{3}$. Sete anos mais tarde, no estado mineiro, criava-se a Universidade de Minas Gerais (1927), seguindo o mesmo modelo adotado pela Universidade do Rio de Janeiro, isto é, o agrupamento de escolas já existentes.

Ressaltamos que, segundo Olive (2002), estas universidades pioneiras detinham caráter elitista, instaladas em cidades que ocupavam significativa importância na economia do país e não acatava outras discussões que não estivessem no âmbito do tripé dos primeiros cursos

2 A Reforma Carlos Maximiliano, "por meio do Decreto $\mathrm{n}^{\circ} 11.530$, dispõe a respeito da instituição de uma universidade, determinando em seu art. $6^{\circ}$ : 'O Governo Federal, quando achar oportuno, reunirá em universidade as Escolas Politécnica e de Medicina do Rio de Janeiro, incorporando a elas uma das Faculdades Livres de Direito, dispensando-a da taxa de fiscalização e dando-lhe gratuitamente edifício para funcionar" (FÁVERO, 2006, p. 21).

${ }^{3}$ Segundo Olive (2002, p. 33), a criação desta universidade na cidade do Rio de Janeiro foi empreendida pela visita do Rei da Bélgica "por ocasião dos festejos do Centenário da Independência, havendo interesse político em outorgar-lhe o título de Doutor Honoris Causa". Ou seja, a principal razão da construção de uma universidade partiu de interesses políticos, e não da demanda local.

\begin{tabular}{l|l|l|l|l|l} 
(C) Rev. Inter. Educ. Sup. & Campinas, SP & v.3 & n.3 & 645-677 & set./dez. 2017
\end{tabular}


existentes, ou seja, medicina, direito e engenharia (SILVA, 2014; GHIRALDELLI JÚNIOR, 2001; PERES, 2010), seguindo o modelo universitário francês, o qual suas "instituições seculares [eram] mais voltadas ao ensino do que à pesquisa" (OLIVE, 2002, p. 32). Estas características pautam-se na condição de que a universidade brasileira

[...] foi criada não para atender às necessidades fundamentais da realidade da qual era e é parte, mas pensada e aceita como um bem cultural oferecido a minorias, sem uma definição clara no sentido de que, por suas próprias funções, deveria se constituir em espaço de investigação científica e de produção de conhecimento (FÁVERO, 2006, p. 19).

Este fato direcionou o saber das instituições universitárias para atender os requisitos da classe burguesa. Isto é, a Educação Superior engendrada, além de ser excludente, era direcionada para atender essa elite. Outro ponto, de merecido destaque, é o tardio empenho dos governantes na inauguração de instituições universitárias no país, sendo justificado pela ideologia positivista incutida no posicionamento político daqueles que precederam a proclamação da República (OLIVE, 2002; SILVA, 2014).

Pontuamos o início da Educação Superior no Brasil com a criação de duas IES's, portanto, apontamos a gênese do acesso a este nível de ensino como sendo uma demanda da Realeza, porém não somente dela, uma vez que "os anos 30 marcaram a consolidação da sociedade urbano industrial brasileira e a criação de novos empregos urbanos tanto no setor público como no privado" (OLIVE, 2002, p. 37), impulsionando a classe operária a reivindicar qualificação para a sua força de trabalho. Por sua vez, este acesso não remete-se apenas ingressar no meio acadêmico, mas também permanecer nele, o que acarreta a

[...] necessária a criação de mecanismos que garantam a permanência dos que nela ingressam, reduzindo os efeitos das desigualdades apresentadas por um conjunto de estudantes, provenientes de segmentos sociais cada vez mais pauperizados e que apresentam dificuldades concretas de prosseguirem sua vida acadêmica com sucesso (ALVES, 2002, p. 06).

Com isto, formula-se políticas para a Assistência Estudantil que, porquanto, não atendem sua demanda, possuindo caráter paliativo, burocrático e aspecto deficitário de recursos financeiros, carecendo de uma organização voltada para assegurar efetivamente a permanência.

Cabe explicitar que, a Assistência Estudantil difere, em alguns pontos, da Assistência Social ${ }^{4}$, já que ela encontra-se voltada para atender às demandas decorridas das desigualdades sociais,

\footnotetext{
${ }^{4}$ Política Pública que visa a garantia dos mínimos sociais. Possui caráter focalista e seletivo, destinada para quem dela precisar (BEHRING; BOSCHETTI, 2011).

\begin{tabular}{l|c|c|c|c|c|} 
(C) Rev. Inter. Educ. Sup. & Campinas, SP & v.3 & n.3 & $645-677$ & set./dez. 2017 \\
\hline
\end{tabular}
}


advindas do acesso ao ensino superior por parte da classe trabalhadora, democratizando o acesso a este nível de ensino e evitando a evasão destes sujeitos (SILVEIRA, 2012).

No Brasil, os primórdios da política de Assistência Estudantil encontram-se na inauguração da Casa do Estudante do Brasil ${ }^{5}$, no Rio de Janeiro, em 1930, "era um casarão com três andares que possuía um restaurante popular frequentado por estudantes 'carentes' e membros da comunidade que se faziam passar por alunos, para poderem realizar as refeições na casa" (Idem, p. 52). Diante deste panorama, seguiremos nosso estudo com este ensejo de articular o desenrolar da política de Assistência Estudantil atrelada expansão do Ensino Superior, uma vez que esta política avança conforme as demandas estudantis.

\section{UNIVERSIDADE E ESTADO DEMOCRÁTICO}

Como é sabido, Getúlio Vargas reconheceu inúmeros direitos sociais, dentre eles a saúde e a educação, criando, em 1930, o Ministério da Educação e Saúde Pública, tendo a sua frente Francisco Campos (SILVA, 2014). Este ministro promoveu inúmeras transformações no âmbito educacional: instituiu uma reforma da Educação Superior e regulamentou a assistência à(ao) estudante, configurando-se ações pioneiras na história da garantia do direito à educação brasileira (SILVEIRA, 2012).

Para tanto, o ensino superior esteve organizado, inicialmente, pelos seguintes decretos: Estatuto das Universidades Brasileiras (Decreto-lei $\mathrm{n}^{\circ}$. 19.851/31), organização da Universidade do Rio de Janeiro (Decreto-Lei no . 19.852/31) e criação do Conselho Nacional de Educação (Decreto-Lei $n^{\circ}$ 19.850) (SILVEIRA, 2012), visando a organização e regulamentação deste ensino, bem como a oferta da assistência às(aos) estudantes. Contudo, estas iniciativas, conforme Fávero (2006, p. 23),

Trata-se, sem dúvida, de adaptar a educação escolar a diretrizes que vão assumir formas bem definidas, tanto no campo político quanto no educacional, tendo como preocupação desenvolver um ensino mais adequado à modernização do país, com ênfase na formação de elite e na capacitação para o trabalho.

Naquela década (1930), os cursos eram ofertados em escolas separadas e pagava-se uma taxa para ter acesso ao ensino. Com a Reforma Francisco Campos (1931), estes cursos passaram a ser ofertados em estabelecimentos, que tinham em comum uma reitoria (OLIVE, 2002). Este modelo educacional esteve afiançado a um sistema moderno conservador, que pregava o desenvolvimento econômico do país, atendendo as demandas do capital monopolista.

\footnotetext{
${ }^{5}$ No entanto, as primeiras iniciativas de Assistência Estudantil, datam de 1928, com a construção da Casa do Estudante Brasileiro, em Paris, sendo destinada para os filhos da elite que estudavam na França (SILVEIRA, 2012), ou seja, tal assistência, em sua origem, esteve atrelada aos anseios da elite brasileira.

\begin{tabular}{l|l|l|l|l|l|} 
(C) Rev. Inter. Educ. Sup. & Campinas, SP & v.3 & n.3 & $645-677$ & set./dez. 2017 \\
\hline
\end{tabular}
}


Destacamos aqui o Estatuto das Universidades Brasileiras, o qual reconheceu a necessidade da Assistência Estudantil, instituindo auxílios arrecadados da sociedade de professores e repassados para estudantes carentes com bom desempenho (PINTO; DAVID; MACHADO, 2015). Entretanto, não vinculava-se uma percepção de direito, considerada como concessões e ajudas do governo, que possuía interesse em ter o apoio das(os) estudantes, sendo que este já contava com o apoio da Igreja, uma vez que esta instituição era a responsável pela "formação humanista da elite brasileira" (SILVA, 2014, p. 23), possibilitando o poder centralizador do Estado Novo.

Datam, deste mesmo ano e do seguinte, a criação da Universidade de São Paulo (1934) e a Universidade do Distrito Federal ${ }^{6}$ (1935), caracterizadas como instituições que buscaram adquirir autonomia frente ao poder centralizado e autoritário do então governo e que almejavam o viés de formação científica, preconizando a pesquisa em relação aos problemas nacionais (SILVA, 2014; OLIVE, 2002). Neste contexto, em 1937, foi criada, pelo incentivo do Ministério da Educação (MEC), a União Nacional dos Estudantes (UNE), que tornou-se importante entidade para com as lutas e reivindicações estudantis (ARAÚJO, 2007), relacionadas a Assistência Estudantil.

\begin{abstract}
Segundo a UNE (2004), a assistência estudantil deve ser compreendida como Política Pública fundamental não só à permanência, mas, também, à formação completa dos estudantes. Seu foco não pode ser o indivíduo, mas a coletividade. Dessa forma, para muito além das bolsas de auxílio, fazem-se necessários investimentos em Restaurantes Universitários administrados pela Comunidade Acadêmica; Moradias Estudantis ampliadas e revitalizadas; Creches; Espaços gratuitos e acessíveis para o desenvolvimento de atividades culturais e esportivas; Bibliotecas completas e com qualidade; garantia de transporte; assistência médica, odontológica e psicológica; e de acesso e permanência aos portadores de necessidades físicas especiais (SANCHES, 2014, p. 13).
\end{abstract}

Ou seja, a entidade representativa da categoria estudantil defendia a assistência, para as demandas do alunado, voltada não somente para a permanência do sujeito, mas também pelo zelo do seu emocional. Ressaltamos que, as ações destinadas para esta instância consideravam aspectos discutidos durante o II Congresso Nacional dos Estudantes, ocorrido em 1938, no qual

[...] foi aprovado um plano de reforma educacional que pretendia solucionar problemas educacionais, auxiliando os estudantes com dificuldades econômicas, o que sinalizava o início de uma conscientização por parte dos estudantes da importância que deve se (sic) dada à assistência estudantil nas universidades brasileiras (SILVEIRA, 2012, p. 53).

${ }^{6}$ Extinta em 1939, por não ser condizente as normalizações do MEC (SILVA, 2014).

\begin{tabular}{l|l|l|l|l} 
(C) Rev. Inter. Educ. Sup. & Campinas, SP & v.3 & n.3 & 645-677
\end{tabular}

set./dez. 2017 
Assistência Estudantil não foi apenas incentivada pelo MEC, mas um requerimento do público das IES's. Ora, diante de um contexto imbricado de desigualdades sociais e econômicas, a união dos sujeitos, imersos nas diferentes realidades locais, acabaram ocasionando exigências para possibilitar o seu acesso e sua permanência no meio universitário burguês e seletivo. Estas ações, de teor assistencialistas, passam a ser consideradas como direito de acesso ${ }^{7}$ integrante da política educacional, a partir de 1961, com a formulação da Lei de Diretrizes e Base para a Educação Nacional (LDB).

A partir disso, o Estado, além de ser responsável pela ampliação das oportunidades de vagas para o ingresso na Educação Superior, foi responsabilizado por traçar possibilidades, estrutura e programas para a permanência destas(es) estudantes, visando a qualidade do ensino, além de assegurar a igualdade de oportunidade para todas(os) e "[...] serviços de assistência social, médico-odontológico e de enfermagem aos alunos" (Art. 90, Lei 4. 024/61-LDB). Outro avanço desta lei, esteve em assegurar a participação da comunidade estudantil nos colegiados:

Nesse contexto, a participação do movimento estudantil se dá de forma muito densa, o que torna difícil analisar a história do movimento da Reforma Universitária no Brasil sem que seja levada em conta essa participação. Dos seminários e de suas propostas, fica evidente a posição dos estudantes, através da UNE, de combater o caráter arcaico e elitista das instituições universitárias (FÁVERO, 2006, p. 29).

Porquanto, apesar destes incipiente avanços, a LDB de 1961 não acarretou vantajosas mudanças no âmbito da estrutura da Educação Superior, haja vista a manutenção da organização universitária e o direcionamento privilegiado para o ensino, sem avançar no campo da pesquisa (OLIVE, 2002). Este fato não configurou-se como entrave para a expansão da Educação Superior, haja vista que a política expansionista desta época - 1950 a 1960 - coadunava com as imposições exteriores sobre os aspectos sociais e econômicos (MENDONÇA, 2000), os quais perpassavam o interim da República. Depreende-se que esta expansão foi

[...] uma resposta ao aumento da demanda ocasionado pelo deslocamento dos canais de ascensão social das camadas médias e pela própria ampliação do ensino médio público, bem como pelo alargamento do ingresso na universidade decorrente do processo de equivalência dos cursos técnicos ao curso secundário, que se iniciou nos anos 50 e culminou com a Lei de Diretrizes e Bases de 1961(Idem, p. 142).

\footnotetext{
${ }^{7}$ Carlos Simões (2014) aborda um salutar tema referente à concepção de direito de acesso, que são direitos que tutelam a garantia dos direitos sociais, isto é, que subsidiam, por intermédio de legislações específicas, os direitos fundamentais, possibilitando a sua integral garantia. Exemplo: o direito à saúde é tutelado por leis como a humanização do sistema único, a garantia de acompanhante durante o parto. Assim, a assistência estudantil configura-se como direito de acesso ao possibilitar condições para que os sujeitos possam usufruir do seu direito à educação.
}

\begin{tabular}{|l|l|l|l|l|l} 
(C) Rev. Inter. Educ. Sup. & Campinas, SP & v.3 & n.3 & 645-677 & set./dez. 2017
\end{tabular}


É pertinente frisar a existência de conjunto de ações, sediadas por professoras(es) e estudantes, voltadas para transmutar o caráter das IES's elitizadas para serem democráticas e populares, como exemplo temos os Centros Populares de Cultura, que realizaram a Campanha Alfabetização de Adultos, com o propósito de democratizar o conhecimento (SILVA, 2014; ARAÚJO, 2007).

Democratizar o conhecimento e desenvolver o ensino eram as questões principais da década de 1960, incorrendo na Reforma Universitária de 1968. Vejamos alguns elementos que impulsionaram a necessidade de uma reorganização das universidades neste recorte histórico, incutido de interesses capitalistas, em meio ao regime militar e frente as mutações acometidas a sociedade brasileira:

[...] a tomada de consciência, por parte de vários setores da sociedade, da precariedade em que se encontravam as universidades brasileiras; o ritmo acelerado do desenvolvimento do país, em decorrência da industrialização e do crescimento econômico, que demandavam um número crescente de mão de obra qualificada; as transformações, tanto no campo sociocultural quanto no campo econômico; a discussão ocorrida durante o processo de tramitação do Projeto de Lei da LDB, que envolvia calorosos debates sobre escola pública versus escola privada; a instituição da Universidade de Brasília através da Lei no. 3.998, de 15 de dezembro de 1961, considerada um divisor de águas na história das universidades, que se constituiu na primeira universidade que não foi criada mediante a aglutinação de outras faculdades que já existiam - a universidade possuía uma estrutura considerada flexível, moderna e integrada, onde os departamentos substituíram as tradicionais cátedras; a participação ativa do movimento estudantil, combatendo o caráter arcaico e elitista das universidades (OLIVE, 2002; FÁVERO 2004; FÁVERO, 2006). [...] pressão da classe média para ampliar o número de vagas no Ensino Superior, que atendia a toda a demanda, e mediante a necessidade requerida pelo projeto de modernização econômica que se queria implementar no Brasil (SILVA, 2014, p. 27-28).

Além desses fatores, o Brasil vivenciou a pressão estudantil por uma reforma universitária a fim de democratiza-la e "transformá-la num instrumento para desenvolvimento do país" (ARAÚJO, 2007, p. 103), buscando soluções para os seus problemas sociais e educacionais. Este posicionamento pressionou a criação de um Grupo de Trabalho, que discutisse meios de superar a crise da universidade brasileira.

O Grupo de Trabalho chegou à conclusão da inflexibilidade da universidade brasileira e sua incapacidade de atender as demandas do mercado de trabalho, o qual requisitava mão de obra qualificada e diferenciada para cada setor (FÁVERO, 2006). Tais dimensões, motivaram a promulgação da Lei 5. 540/68, Lei da Reforma Universitária de 1968, a qual fixou a garantia da gratuidade do ensino e a indissociabilidade do ensino, pesquisa e extensão (DAHMER, 2007). Conforme Fávero (2006, p. 34), 
Entre as medidas propostas pela Reforma, com o intuito de aumentar a eficiência e a produtividade da universidade, sobressaem: o sistema departamental, o vestibular unificado, o ciclo básico, o sistema de créditos e a matrícula por disciplina, bem como a carreira do magistério e a pós-graduação. [...] Por sua vez, embora a cátedra tenha sido legalmente extinta, em muitos casos foi apenas reduzida sua autonomia.

Além deste pontos, destacamos que, nos debates para a formulação da referida reforma, a autonomia universitária obteve respaldo, sem, no entanto, ser consolidada, em decorrência do poder autoritária da ditadura militar (SILVA, 2014).

No que diz respeito ao acesso às universidades, a ampliação das vagas não deu conta da crescente demanda que lhe era imposta, o que acabou por levar aos governantes a incentivar a esfera privada para ofertar, de modo complementar, este ensino (Ibidem), sendo assegurado subsídios públicos para as bolsas estudantis (SILVEIRA, 2012). Na década de 1970, tivemos o boom de expansão das vagas para o ingresso nas IES's, como afirma Vasconcelos (2010, p. 401):

\footnotetext{
Entre as décadas de 50 a 70 criaram-se universidades federais em todo o Brasil, ao menos uma em cada estado, além de universidades estaduais, municipais e particulares. A descentralização do ensino superior foi à vertente seguida na Lei de Diretrizes e Bases da Educação Nacional, em vigor a partir de 1961(Lei nº. 4024). Mas a explosão do ensino superior ocorreu somente nos anos de 1970. Durante esta década, o número de matrículas subiu de 300.000 (1970) para um milhão e meio (1980). A concentração urbana e a exigência de melhor formação para a mão-deobra industrial e de serviços forçaram o aumento do número de vagas e o Governo, impossibilitado de atender a esta demanda, permitiu que o Conselho Federal de Educação aprovasse milhares de cursos novos.
}

Identificamos, assim, não só a expansão das IES's como forma de abarcar todas(os) aquelas(es) que almejavam adquirir formação profissional de nível superior, apreendemos também que isto significou a crescente ampliação do setor privado, passando a contar com a oferta de um número maior de instituições quando equiparado ao de IES's públicas. Este fato assinalou a mercantilização, precarização e insuficiente fiscalização destinada para este ensino (VASCONCELOS, 2010).

Com a promulgação da Constituição Federal de 1988, "as universidades gozam de autonomia didático-científica, administrativa e de gestão financeira e patrimonial, e obedecerão ao princípio da indissociabilidade entre ensino, pesquisa e extensão" (BRASIL, 2013, Art. 207). Neste interim, a Constituição Cidadã, em seu artigo 206, trata do acesso à educação considerando alguns princípios, dentre eles destacamos a "igualdade de condições para o acesso e permanência na escola" (BRASIL, 2013), regulamentando, assim, a assistência estudantil. 
Em 1990, o Brasil abre suas portas para acelerar o processo de consolidação do neoliberalismo, iniciando a massiva privatização das empresas estatais. Com isso, no governo Fernando Henrique Cardoso (FHC), houve a interligação com as "diretrizes do BM e do FMI para a reforma do Ensino Superior" (SHANCHES, 2014, p. 08), as quais previa a extinção dos recursos para a alimentação e moradia e estabelecia a necessidade das(os) alunas(os) arcar com os investimentos feitos na universidade, fortalecendo a mercantilização deste direito.

Desta feita, esta transmutação, da educação de direito para serviço, acarreta a formação de um "nicho lucrativo para uma boa parcela dos(as) empresários(as) no Brasil (ARAÚJO et al, 2016, p. 06)", implementando a consolidação de um capitalismo universitário, que vem a "contribuir massivamente, de forma estratégica, com o funcionalismo a ordem burguesa, voltando-se, prioritariamente, a atender as demandas do mercado" (Idem, p. 13), com o incentivo destes organismos internacionais.

Em 1996, a LDB foi reformulada e acometeu significativas mudanças para o ensino graduado e a assistência às(aos) estudantes:

\footnotetext{
Artigo $3^{\circ}$. O ensino deverá ser ministrado com base nos seguintes princípios:

I - igualdade de condições para o acesso e permanência na escola;

$[\ldots]$

Art. 16. O sistema federal de ensino compreende:

[...]

II - as instituições de educação superior criadas e mantidas pela iniciativa privada;

[...]

Art. 43. A educação superior tem por finalidade:

[...]

II - formar diplomados nas diferentes áreas de conhecimento, aptos para a inserção em setores profissionais e para a participação no desenvolvimento da sociedade brasileira, e colaborar na sua formação contínua;

[...] (BRASIL, 1996).
}

Desse modo, a Educação Superior reafirma o seu viés de preparação para o mundo do trabalho, caracterizando a universidade como espaço que "garante a formação de profissionais para as demandas do mercado e preocupa-se essencialmente com gestão" (AGAPITO, 2016, p. 129). Além disso, esta reformulação da LDB aponta, novamente, a responsabilidade da universidade oferecer um retorno para a sociedade, bem como apresentar soluções para os seus problemas. Outra reafirmação está contida na primazia do Estado frente a Assistência Estudantil, ampliando-a para as instituições privadas. Com o fim do governo FHC e a posse do governo Lula da Silva, no ano de 2002, temos avanços na política de Assistência Estudantil, reafirmando os direitos da juventude, objetivando aniquilar ou amenizar as desigualdades sociais existentes no meio acadêmico, com a ampliação de bolsas e programas destinados para o corpo discente. 
Em linhas gerais, as observações aqui retratadas abrem um leque de discussões acerca da efetividade da política de Assistência Estudantil, regulamentada pelo Decreto $n^{\circ}$ 7. 234/2010, que implementa o Plano Nacional de Assistência Estudantil (PNAES) ${ }^{8}$, que, segundo Vasconcelos (2010, p. 07), constitui-se como uma

\begin{abstract}
conquista [...] fruto de esforços coletivos de dirigentes, docentes e discentes e representou a consolidação de uma luta histórica em torno da garantia da assistência estudantil enquanto um direito social voltado para igualdade de oportunidades aos estudantes do ensino superior público.
\end{abstract}

No entanto, é um campo do direito em que temos uma maior escassez de recursos (CISLAGHI; SILVA, 2012), fazendo-se necessário o seu reconhecimento como direito social, por um lado, e como investimento, por outro, pois "a assistência estudantil, enquanto mecanismo de direito social, tem como finalidade prover os recursos necessários para transposição dos obstáculos e superação dos impedimentos ao bom desempenho acadêmico" (VASCONCELOS, 2010, p. 08). Dentre os mecanismos utilizados para a superação dos obstáculos e desafios impostos pela estrutura social para aquelas(es) oriundas(os) da classe trabalhadora, o PNAES dispõe que:

$\S 1^{\circ}$ As ações de assistência estudantil do PNAES deverão ser desenvolvidas nas seguintes áreas:

I - moradia estudantil;

II - alimentação;

III - transporte;

IV - assistência à saúde;

V - inclusão digital;

VI - cultura;

VII - esporte;

VIII - creche;

IX - apoio pedagógico e

$\mathrm{X}$ - acesso, participação e aprendizagem de estudantes com deficiência, transtornos globais do desenvolvimento e altas habilidades e superdotação (BRASIL, 2010, PNAES, art. $3^{\circ}$ ).

A partir desta discussão, reflitamos: como assegurar a permanência, o cuidado com o emocional das(os) discentes se os programas responsáveis, por esta garantia, não possuem investimentos suficientes para suprir suas demandas com qualidade e eficácia? Esta carência de recursos financeiros é "característico da totalidade das políticas sociais no período, [...] [gerando] à focalização dessas políticas, o que [...] descaracteriza a educação como direito universal" (CISLAGHI; SILVA, 2012, p. 490). Desta forma, estas demandas são submetidas a um processo seletivo e focalista, ocasionando assim a insuficiência da política, reafirmando

\footnotetext{
8 "Implantado em 12 de Dezembro de 2008, é uma das ações oriundas do Plano de Desenvolvimento da Educação - PDE elaborado e implantado no primeiro mandato do governo Lula" (VASCONCELOS, 2010, p. 11).

\begin{tabular}{|l|l|l|l|l|l|} 
(C) Rev. Inter. Educ. Sup. & Campinas, SP & v.3 & n.3 & 645-677 & set./dez. 2017 \\
\hline
\end{tabular}
}


o caráter elitista da universidade, ocupada, majoritariamente, pela burguesia, sendo, essencialmente, a única capaz de permanecer no espaço acadêmico com recursos próprios.

Tendo em vista estes apontamentos, seguiremos nossa discussão sobre as estratégias governamentais implementadas, que visam democratizar as vagas das universidades brasileiras.

\title{
RECONFIGURAÇÃO DO ENSINO SUPERIOR: AVANÇO OU RETROCESSO?
}

Pertinente a explanação realizada anteriormente, é válido enfatizar que as estratégias de democratização, por intermédio de programas governamentais, favorecem a constituição e a consolidação de uma burguesia educacional (DEMO, 1995), ou seja, o surgimento de um grupo de burgueses que ambicionam consolidar alto potencial de lucratividade em todos os níveis de ensino, especificamente, o nível superior, promovendo sua proliferação. Em vista disso,

\begin{abstract}
A combinação de fortes incentivos fiscais ao setor privado, ampliação dos programas assistenciais, ampliação da modalidade de educação à distância, desenvolvimento de programas de crescimento da rede educacional pública, mediante pactos de adesão para recebimento de recursos adicionais, fomento à contratação de crédito para financiamento dos estudos e contratação de assessorias privadas para a elaboração e avaliação de projetos pedagógicos conformam as bases materiais de sustentação desse processo de ampliação (CFESS, 2012, p. 39).
\end{abstract}

A ampliação do sistema educacional brasileiro, essencialmente no que se refere a Educação Superior, tem se apresentado de modo subserviente às demandas do modo de produção vigente: "o processo de adequação do sistema educacional às necessidades de resposta do capital à sua crise contemporânea se desenrola por dentro da contrarreforma do Estado" (KOIKE, 2009, p. 241). A contrarreforma estatal, iniciada em meados da década de 1990, segue a lógica da valorização do capital, a qual demanda cortes nos gastos sociais e maior abertura para o capital internacional. Destarte,

\begin{abstract}
A contrarreforma do Estado brasileiro traz as seguintes implicações para o ensino superior: expansão da privatização da oferta de cursos; liquidação da relação ensino/pesquisa/extensão; concepção das universidades de forma operacional e pragmática; submissão das atividades acadêmicas a lógica do mercado/capital e a autonomia das universidades canalizada para a administração dos recursos financeiros necessários para a manutenção da vida acadêmica (AGAPITO, 2016, p. 128).
\end{abstract}

Estas implicações estão em conformidade com as requisições do BM, que trata a educação com viés economicista e como um instrumento para o alívio da pobreza (LIBÂNEO, 2012; ANDRADE, 2012). Segundo Andrade (2012), esta agência multilateral desenvolve

\begin{tabular}{|l|l|l|l|l|l} 
(c) Rev. Inter. Educ. Sup. & Campinas, SP & v.3 & n.3 & $645-677$ & set./dez. 2017 \\
\hline
\end{tabular}


orientações e metas para os países periféricos alcançarem patamares satisfatórios na oferta da educação superior com qualidade, sem, no entanto, investir altos recursos financeiros. Neste âmbito,

A expansão da educação superior faz parte do conjunto de metas acordadas entre o governo brasileiro, Banco Mundial e FMI, resultando na implantação dos seguintes programas: Programa Universidade para Todos (PROUNI); o Fundo de Financiamento ao Estudante do Ensino Superior (FIES); o Programa Universidade Aberta do Brasil (UAB) e o Programa de Apoio a Planos de Reestruturação e Expansão das Universidades Federais (Reuni) (AGAPITO, 2016, p. 132).

Além das privatizações, temos também a precarização do ensino público, por meio de condições de trabalho inadequadas, baixos salários, greves constantes, ineficientes programas de Assistência Estudantil, dentre outros. Diante deste cenário, de subalternidade das decisões governamentais aos ditames do sistema econômico, que possui sua maior representatividade nos organismos internacionais, inúmeras consequências negativas são acarretadas para a classe trabalhadora, repercutindo em seu acesso e permanência na universidade.

Vejamos, então, estas iniciativas que promulgam o desmonte da política de educação pública, gratuita, universal e de qualidade:

\section{a) Programa de Apoio a Planos de Reestruturação e Expansão das Universidades Federais (REUNI)}

O REUNI, implementado pelo decreto 6. 096 de 2007, visa à amplificação das instalações de unidades de ensino superior, dotando “[...] as universidades federais das condições necessárias para ampliação do acesso e permanência na educação superior [...]" (Grupo Assessor, 2007). Seu objetivo é:

Criar condições para a ampliação do acesso e permanência na educação superior, no nível de graduação, para o aumento da qualidade dos cursos e pelo melhor aproveitamento da estrutura física e de recursos humanos existentes nas universidades federais, respeitadas as características particulares de cada instituição e estimulada a diversidade do sistema de ensino superior (Idem, p. 10).

Consoante a isso, o REUNI almeja a oferta de cursos superiores estabelecendo padrões mínimos a serem cumpridos pelas IES's, visando a qualidade do rendimento escolar, bem como as condições de permanência. É o aumento das vagas nas IES's mediante contrato entre instituições e governo por intermédio de metas a serem alcançadas. Estas metas são voltadas para diminuir o número de estudantes evasivos e repetentes, bem como aumentar o número de ingressantes na Educação Superior, sem deter-se aos 
[...] déficits anteriormente acumulados nos orçamentos de custeio e pessoal. [...] A expansão proposta, porém, está atrelada a uma reestruturação da universidade para os padrões requisitados pelo capitalismo, em sua fase atual, materializados nas propostas do Banco Mundial (CISLAGHI; SILVA, 2012, p. 497).

Ou seja, não é uma questão de expandir e democratizar o espaço acadêmico, mas de atender as propostas impostas pelo capital internacional. As autoras Cislaghi e Silva (2012) assinalam que, a Assistência Estudantil, estabelecida por este programa, apresenta-se de forma focalizada e seletiva, excluindo estudantes que necessitam da mesma. Este fenômeno ocorre pelo fato da divisão existente entre os sujeitos pauperizados e aqueles assalariados, em uma lógica que retira a universalização do campo educacional.

\section{b) Fundo de Financiamento ao Estudante do Ensino Superior (FIES)}

O FIES, conforme Leher (2013), foi sancionado pelo presidente Fernando Henrique Cardoso (1996-2001), em 1999, permanecendo cada vez mais consolidado até os dias atuais, financiando o pagamento das mensalidades de estudantes de baixa renda, com juros reduzidos e prazo alongado (MEC/SESu/DIPES, 2015). Constitui-se uma afronta ao direito à educação pública, tendo em vista a mercantilização do ensino.

Nesta parceria público-privado, o Estado deixa de ser promotor da Educação Superior, para tutelar a oferta da mercadoria existente nas instituições privadas de ensino. Ou seja, o Estado tornar-se salvador, da falência eminente, de empresas educacionais. Esta postura está em harmonia com o raciocínio do BM, que defende a premissa de que "o Estado é essencial para o desenvolvimento econômico e social, não como promotor direto do crescimento, mas como parceiro, catalisador e facilitador" (BANCO MUNDIAL, 1997, p. 01).

Segundo Queiroz (2013, p. 05), esta lógica destruirá o setor público ao criar mecanismos legais que assegurem mudança no papel do Estado, frente a garantia dos direitos sociais, "sob o discurso de que em muitos países, os monopólios públicos de infraestruturas, serviços sociais e outros bens e serviços tem poucas probabilidades de ser eficazes". Desta forma, o FIES configura-se como um incentivo ao setor privado para substituir o Estado e ofertar serviços educacionais.

\section{c) Programa Universidade para Todos (PROUNI)}

O PROUNI, criado no primeiro mandato do governo Lula (2002-2006), em 2004, foi institucionalizado pela Lei 11.069 de 2005 e dispõe sobre a concessão parcial e/ou integral de bolsas para o financiamento de cursos de graduação de administração privada, para

n.3

$645-677$
set./dez. 2017 
estudantes que cursaram o ensino médio em escolas públicas ou para aquelas(es) que estudaram no ensino particular, em condição de bolsista.

O Prouni possui também ações conjuntas de incentivo à permanência dos estudantes nas instituições, como a Bolsa Permanência, o convênio de estágio MEC/CAIXA e a Federação Brasileira de Bancos (Febraban) e o Fies - Fundo de Financiamento ao Estudante do Ensino Superior, que possibilita ao bolsista parcial financiar a parcela da mensalidade não coberta pela bolsa do programa (MEC/SESu/DIPES, 2015 p. 02).

Tal programa, retira o protagonismo estatal na oferta de uma educação para todas(os) em instituições públicas, na medida que direciona investimentos, com os recursos advindos dos impostos, para a esfera privada promover o Ensino Superior sob a lógica de gratuidade e democratização do acesso à universidade. Isto é "nada mais [...] do que a compra de vagas em universidade privada com recursos públicos, dando em troca ampliação da isenção fiscal aos empresários da educação" (QUEIROZ, 2013, p. 05), ou seja, investimento direto na esfera privada, em prol da inclusão de estudantes da classe trabalhadora, oferecendo em troca a não repartição, em forma de arrecadação de impostos, nos lucros obtidos.

\section{d) Universidade Aberta do Brasil (UAB)}

Além destes programas que arrebatam a primazia do Estado, assim como estabelecem a mercantilização da educação, temos também a instituição de uma nova forma de ensino que, segundo Koike (2009, p. 244), "cria dois tipos de ensino, de formação, de aluno e de docente". Esta modalidade configura-se como uma formação de caráter superior e currículo mínimo, transgredindo princípios como a indissociabilidade entre ensino, pesquisa e extensão, o estágio supervisionado, dentre outros.

A promulgação do Decreto de $n^{\circ} 5.800$ de 2006, que dispõe sobre a Universidade Aberta do Brasil (UAB), com o intuito "de expandir e interiorizar a oferta de cursos e programas de educação superior no País” (BRASIL, 2006, Art. $1^{\circ}$ ), rebate diretamente no avanço desmedido do sistema EaD, com a falsa ideia de democratização do acesso ao ensino superior, direcionando-o para as demandas do mercado e formando apenas para a dimensão técnico-operativa, uma vez que esta formação é minimalista, aligeirada e tecnicista (KOIKE, 2009).

Esse acesso massificado, todavia, significa uma redução da qualidade defendida pelos movimentos sociais e inscrita na Constituição de 1988, que é calcada na indissolubilidade entre ensino, pesquisa e extensão. Também não garante princípios pedagógicos básicos, como o ensino presencial, condições infraestruturais adequadas, professores suficientes (CISLAGHI; SILVA, 2012, p. 498). 
É importante esclarecer que não pretendemos deturpar o avanço tecnológico, haja vista que, por exemplo, no âmbito da política de assistência social, a incorporação das avançadas tecnologias tem sido uma estratégia utilizada para o levantamento de informação, a avaliação e o monitoramento da operacionalização desta política, possibilitando o controle social e evitando as velhas práticas de favores políticos e caridade recorrentes ao passado da Assistência Social (BRASIL, PNAS, 2009).

No campo educacional, tais tecnologias auxiliam o desempenho para melhorar e qualificar o ensino, entretanto, o uso das ferramentas tecnológicas no processo integral da educação, em especial no nível superior, implementa uma modalidade de ensino que flexibiliza as práticas educativas, reduzindo-as a vídeo aulas que perpassam toda formação em um curso superior.

Desta feita, consentimos que os programas mencionados seguem a tendência da educação como mercadoria, precarização do ensino, sendo fiel aos ditames dos organismos multilaterais, permutando a noção de educação como direito social, político e civil (DRUMOND, 2012) para a noção econômica de investimento e, como tal, atrelada a relação custo-benefício. Nesta relação, massifica-se o acesso à educação com reduzido repasse de recursos financeiros, escamoteando a qualidade do processo educativo.

As estratégias de ampliação do acesso à educação escolarizada, em todos os níveis da política educacional, ainda não configuram um efetivo processo de universalização do acesso a esta política, mas uma ampliação desigual em sua escala e, sobretudo, em sua dimensão pública. Está longe, portanto, de ser tomada como uma afirmação da educação pública como um direito social (CFESS, 2012, p. 39).

Vale ressaltar que, tais iniciativas são passíveis de mérito, porém não anulam a necessária responsabilidade do Estado frente aos direitos sociais. Responsabilidade esta rapinada pelo repassa da financeirização da educação para instituições privadas, relegando as instituições públicas para a precarização do ensino superior, o sucateamento estrutural, o limitado e ineficiente repasse de verbas, a carência de políticas de Assistência Estudantil que possuam eficácia e efetividade diante a sua demanda.

Assim, referente a assistência à(ao) estudante, as políticas, programas e benefícios voltados para a Assistência Estudantil no meio acadêmico, no contexto de mercantilização do Ensino Superior, se veem em um dilema ameaçador: de um lado, a ampliação das possibilidades de acesso à educação superior, atendendo os anseios da classe trabalhadora, constitui-se um processo de enorme relevância no campo do direito a esta classe, promovendo oportunidades de inserção neste nível de ensino que, como vimos, era destinado exclusivamente para a classe dominante. Por outro lado, temos uma ampliação distorcida do acesso aos bancos acadêmicos, em que garante-se a possiblidade de ingresso nas IES's, porém nega-se a gratuidade, a universalidade e a equidade assegurados pelos dispositivos legais.

(c) Rev. Inter. Educ. Sup.

Campinas, SP $\mid$ v.3

n. 3

645-677

set./dez. 2017 
Portanto, é possível afirmar que o dilema da Assistência Estudantil, direcionada ao nível superior, configura-se como uma política pública destinada a efetuar-se no meio privado, em decorrência da expansão da escolarização superior neste setor, e fadada ao financiamento insuficiente na esfera pública. Ou seja, "fica evidenciado que a assistência estudantil está associada aos rebatimentos da política econômica vigente (neoliberal), sendo cada vez mais tratada como um "serviço", portanto, passível de mercantilização" (KOWALSKI, 2012, p. 102). Pensemos, então, como garantir a permanência na universidade de estudantes, oriundos dos segmentos populares, que ingressam em IES particulares por intermédio das iniciativas estatais?

Esta é uma questão instigante, uma vez que o empenho estatal visa "injetar" nas IES's sujeitos pertencentes a segmentos sociais poucos presentes no meio acadêmico, por meio de programas que financiam estudos nas universidades particulares, contudo suas ações assistenciais são, majoritariamente, direcionadas para o setor público. Com isso, inferimos que estes estudantes terão seu ingresso "garantido", todavia não poderão usufruir do mesmo.

\section{CONSIDERAÇóES FINAIS}

A discussão que travamos aqui, chama-nos a atenção para o desmonte da política pública educacional, uma vez que os recursos dos cofres públicos são repassados para a esfera privada através dos referidos programas, enquanto as universidades públicas vivenciam um crescente sucateamento estrutural, precarização do seu ensino e desvalorização do seu corpo discente e docente.

Neste contexto, o direito à Educação Superior vem sofrendo arduamente a dicotomia em realizar-se por completo, viabilizando, juntamente com outros aportes, a emancipação humana, ou relegar-se a ser um mecanismo burguês, utilizado para difundir os ideais da ordem vigente, bem como mecanismo para apaziguar os conflitos sociais a partir da sua naturalização. Naturalizar a negação deste direito é fundamental para o sistema capitalista que transforma o ensino graduado em "um dos principais instrumentos de difusão do projeto burguês de sociabilidade e um promissor campo de exploração lucrativa, especialmente nos países da periferia do capitalismo" (QUEIROZ, 2013, p. 06).

O Brasil dispõe de programas que favorecem esta mercantilização, sendo maquiados pela falsa democratização do acesso à universidade, tendo em vista a subtração da qualidade, gratuidade e universalidade deste direito social. Outro contraponto a esta democratização avessa encontra-se no aspecto de incrementarem meios de cursar uma graduação olvidando a necessária manutenção no estabelecimento.

\begin{tabular}{|l|l|l|l|l|l|} 
(C) Rev. Inter. Educ. Sup. & Campinas, SP & v.3 & n.3 & 645-677 & set./dez. 2017 \\
\hline
\end{tabular}


Para muitos, o estabelecimento do FIES, PROUNI e a EaD são formas de expandir o ensino superior para as classes populares, em uma crescente democratização do acesso à universidade. No entanto, esta reconfiguração do ensino superior brasileiro tende a provocar o desmonte da política de educação ao passo em que os recursos públicos, que financiam essa política, são redirecionados para a geração de lucro, a partir da mercantilização deste direito em sua crescente massificação. Outro ponto de suma importância é que estas ações desconsideram que o acesso à academia é muito além do ingresso, necessitando de políticas voltadas para a permanência dos sujeitos da classe trabalhadora.

Democratizar, assim, não é apenas ofertar acesso à educação superior, seja por meio do FIES, PROUNI ou da EaD. A democratização da universidade requer políticas e ações que visem assegurar a permanência em seu espaço, viabilizando condições favoráveis para um satisfatório rendimento.

Por conseguinte, a formulação e implementação da política de Assistência Estudantil configura-se como uma vitória da comunidade acadêmica, porquanto, emana investimentos que possam atender satisfatoriamente a demanda que lhe chega, em decorrência das desigualdades sociais.

Assim, esta política detém papel primordial na eliminação das barreiras fincadas no período imperial e na construção de possibilidades que visem uma universidade não elitista, seletiva e excludente. A construção de uma universidade democrática, para que todas(os) possam ter oportunidades iguais e equânimes, requer ações estatais comprometidas em assegurar a qualidade e universalização da garantia do direito à educação, bem como ações que visem romper com as amarras capitalistas, promovendo a emancipação humana e a autorrealização do indivíduo.

\section{REFERÊNCIAS}

AGAPITO, Ana Paula Ferreira. Ensino Superior no Brasil: expansão e mercantilização na contemporaneidade. Temporalis, Brasília, ano 16, n. 32, 2016. Disponível:

<http://periodicos.ufes.br/temporalis/article/view/14064>. Acesso em: 15 dez. 2016.

ALVES, Jolinda Moraes. A assistência estudantil no âmbito da política de Ensino Superior Pública. Serviço Social em Revista, Londrina, v. 5, n. 1, 2002. Disponível em: <http://www.ssrevista.uel.br $>$. Acesso em: 20 dez. 2016. 
ANDRADE, Maria Edigleuma. Política de expansão da UERN: oferta e qualidade da Educação Superior. 2012. 250 p. Tese (Doutorado em Educação) - Centro de Educação, Universidade Federal da Paraíba, João Pessoa, 2012.

ARAÚJO, Maria Luciene da Silva et al. Ensino à Distância e os seus rebatimentos no curso de Serviço Social: educação de qualidade? In: CONGRESSO BRASILEIRO DE ASSISTENTES SOCIAIS, 15: 2016: Olinda. Anais... Olinda: CFESS/ABEPSS, 2016. CDROM. (80 anos do Serviço Social no Brasil: "a certeza na frente, a história na mão")

ARAÚJO, Maria Luciene da Silva; LEITE, Maria Suzana Sousa. O ensino superior na sociedade brasileira contemporânea. In: SEMINÁRIO REGIONAL DE FORMAÇÃO PROFISSIONAL E MOVIMENTO ESTUDANTIL DE SERVIÇO SOCIAL, 11.: 2016: Mossoró. Anais [do...]. Mossoró: Edições UERN, 2016. (Se faz caminho ao caminhar: lutas e trajetória ético-política do Serviço Social no Brasil).

ARAÚJO, Maria Paula. Memórias estudantis: da fundação da UNE aos nossos dias. Rio de Janeiro: Relume Dumará, 2007. 308 p. ISBN: 9788573164763.

BANCO MUNDIAL. Relatório sobre o desenvolvimento mundial: o Estado em um mundo em transformação. Washington, 1997. 286 p. ISBN: 0821337777. Disponível em: $<$ http://documents.worldbank.org/curated/en/634101468162557539/pdf/341310PORTUGUE 18213137771701PUBLIC1.pdf >. Acesso em: 24 jul. 2017.

BEHRING, Elaine Rosetti. BOSCHETTI, Ivanete. Política social: fundamentos e história. 9. ed. São Paulo: Cortez Editora, 2011. 213 p. (Biblioteca Básica de Serviço Social; v.2). ISBN: 9788524912597.

BRASIL. Constituição da República Federativa do Brasil de 1988. Brasília: Gráfica Senado, 2013. 111 p.

BRASIL. Decreto no 5.800, de 8 de junho de 2006. Dispõe sobre o Sistema Universidade Aberta do Brasil - UAB. Brasília, 2006.

BRASIL. Decreto No 7.234, de 19 de julho de 2010. Programa Nacional de Assistência Estudantil-PNAES. Brasília, 2010.

BRASIL. Lei 4.024, de 20 de dezembro de 1961. Estabelece as Diretrizes e Bases da Educação Nacional. Brasília, 1961.

BRASIL. Lei 9. 394, de 20 de dezembro de 1996. Estabelece as Diretrizes e Bases da Educação Nacional. Brasília, 1996.

BRASIL. Ministério da educação. Secretaria de Educação Superior. Diretoria de Pesquisas Sociais. Manual do Bolsista PROUNI. Coordenação Geral de Projetos Especiais para a Graduação. Brasília, Outubro, 2015. 
BRASIL. Política Nacional de Assistência Social PNAS/ 2004. Brasília, Novembro 2005. CISLAGHI, Juliana Fiuza; SILVA, Mateus Thomaz da. O Plano Nacional de Assistência Estudantil e o Reuni: ampliação de vagas versus garantia de permanência. SER Social, Brasília, v. 14, n. 31, 2012. Disponível em:

<http://periodicos.unb.br/index.php/SER_Social/article/download/7103/6489>. Acesso em: 25 nov. 2016.

CFESS. CONSELHO FEDERAL DE SERVIÇO SOCIAL. Subsídios para a atuação de assistentes sociais na política de educação. 3. série: Trabalho e Projeto Profissional nas políticas sociais. Grupo de Trabalho Serviço Social na Educação. [Brasília], 2012. 66 p.

DAHMER, Larissa. Política educacional brasileira e Serviço Social: do Confessionalismo ao empresariamento da Formação Profissional. 2007. 378 p. Tese (Doutorado em Serviço Social) - Escola de Serviço Social, Universidade Federal do Rio de Janeiro, Rio de Janeiro, 2007.

DEMO, Pedro. Cidadania assistida e cidadania tutelada. Campinas, SP: Autores Associados, 1995. 180 p. ISBN: 9788585701123.

DRUMOND, José Geraldo de Freitas. Educação Superior. In: CASTRO, Carmem Lúcia Freitas de; GONTIJO, Cynthia Rúbia Braga; AMABILE, Antônio Eduardo de Noronha. (Org.). Dicionário de políticas públicas. Barbacena, SP: EdUEMG, 2012. 242 p. ISBN: 9788562578175 .

FÁVERO, Maria de Lourdes de Albuquerque. A universidade no Brasil: das origens à Reforma Universitária de 1968. Educar, Curitiba, n. 28, 2006. Disponível:

<http://revistas.ufpr.br/educar/article/download/7609/5423 >. Acesso em: 20 ago. 2016.

GHIRALDELLI JÚNIOR, Paulo. Introdução à educação escolar brasileira: História, Política e Filosofia da Educação. Versão Prévia, 2001. 241 p.

GRUPO ASSESSOR. REUNI: Reestruturação e expansão das universidades federais. Brasília, 2007.

KOIKE, Maria Marieta. Formação profissional em Serviço Social: exigências atuais. In: Serviço Social: Direitos sociais e competências profissionais. Brasília: CFESS/ABEPSS, 2009. 873 p.

KOWALSKI, Aline Viero. Os (des)caminhos da política de Assistência Estudantil e o desafio na garantia de direitos. 2012. 180 p. Tese (Doutorado em Serviço Social) Pontifícia Universidade Católica do Rio Grande do Sul, Faculdade de Serviço Social. Porto Alegre, 2012. 
LEHER, Roberto. A Universidade Reformanda: atualidade para pensar tendências da educação superior 25 anos após sua publicação. Contemporânea de Educação, Rio de Janeiro, vol. 8, n. 16, 2013. Disponível em:

〈http://revistas.ufrj.br/index.php/rce/article/viewFile/1702/1551 >. Acesso em: 22 ago. 2016.

LIBÂNEO, José Carlos. O dualismo perverso da escola pública brasileira: escola do conhecimento para os ricos, escola do acolhimento social para os pobres. Educação e Pesquisa, São Paulo, v. 38, n. 1, 2012. Disponível em:

$<$ http://www.scielo.br/scielo.php?pid=S151797022012000100002\&script=sci_abstract\&tlng=pt>. Acesso em: 24 set. 2016.

MENDONÇA, Ana Waleska Pollo Campos. A universidade no Brasil. Revista Brasileira de Educação, São Paulo, n. 14, 2000. Disponível em:

<http://www.scielo.br/pdf/rbedu/n14/n14a08 >. Acesso em: 22 jul. 2017.

MOURA, Dante Henrique. Educação básica e educação profissional e tecnológica: dualidade histórica e perspectivas de integração. Holos, Natal, ano 23, vol. 2, 2007. Disponível em: <http://www2.ifrn.edu.br/ojs/index.php/HOLOS/article/viewFile/11/110>. Acesso em: 28 out. 2016.

OLIVE, Arabela Campos. Histórico da educação superior no Brasil. In: SOARES, Maria Susana Arrosa (Org.). A educação superior no Brasil. Porto Alegre: Instituto Internacional para a Educação Superior na América Latina e no Caribe, 2002. 303 p. ISBN: 8588468093.

PERES, Tirsa Regazzini. Educação Brasileira no Império In: UNIVERSIDADE ESTADUAL PAULISTA. Caderno de formação: formação de professores educação, cultura e desenvolvimento. Pró reitoria de graduação. Universidade Virtual do Estado de São Paulo. São Paulo, SP: Cultura Acadêmica, 2010. 128 p. ISBN: 9788579830501.

PINTO, Caroline Casagrande; DAVID, Marcus Vinícius; MACHADO, Carla Silva. A Política de Assistência Estudantil no Brasil: o caso da universidade federal de Juiz de Fora. In: COLÓQUIO INTERNACIONAL DE GESTÃO UNIVERSITÁRIA (CIGU), 15.: 2015: Mar del Plara. [Anais...] Mar del Plata, Argentina: [s.n.], 2015. (Desafios da Gestão Universitária no Século XXI).

QUEIROZ, Viviane de. A expansão da Educação Superior e a parceria público-privada: fortalecimento do setor privado no Brasil. In: JORNADA INTERNACIONAL DE POLÍTICAS PÚBLICAS, 6.: 2013: Maranhão. Anais... Maranhão: UFMA, 2013. (O desenvolvimento da crise capitalista e a atualização das lutas contra a exploração, a dominação e a humilhação ). Disponível em: <http://www.joinpp.ufma.br/jornadas/ joinpp2013/JornadaEixo2013/anais-eixo15-impassesedesafiosdaspoliticasdeeducacao/ pdf/aexpansaodaeducacaosuperioreaparceriapublico-privada.pdf $>$. Acesso em: 23 jul. 2017.

ROCHA, Maria Aparecida dos Santos. A Educação Pública antes da Independência. In: UNESP. UNIVERSIDADE ESTADUAL PAULISTA. Caderno de formação: formação de

\begin{tabular}{|l|c|c|c|c|c|} 
(C) Rev. Inter. Educ. Sup. & Campinas, SP & v.3 & n.3 & $645-677$ & set./dez. 2017 \\
\hline
\end{tabular}


professores educação, cultura e desenvolvimento. Pró reitoria de graduação. Universidade Virtual do Estado de São Paulo. São Paulo, SP: Cultura Acadêmica, 2010. 128 p. ISBN: 9788579830501 .

SANCHES, Rodrigo Ruiz. As Políticas de Assistência Estudantil no Brasil. História, Movimento e Reflexão, Barretos, v. 2, n. 1, 2014. Disponível:

<http://www.revistadigital.unibarretos.net/index.php/historia/article/view/28 >. Acesso em: 30 nov. 2016.

SILVA, Priscila Pereira. O novo aluno do ensino superior em um contexto neoliberal. 2014. 222 p. Dissertação (Mestrado em Educação) - Universidade Estadual de Campinas, Faculdade de Educação, Campinas, 2014.

SILVEIRA, Míriam Moreira da. A Assistência Estudantil no ensino superior: uma análise sobre as políticas de permanência das universidades federais brasileiras. 2012. $137 \mathrm{f}$. Dissertação (Mestrado em Política Social) - Centro de Ciências Jurídicas, Econômicas e Sociais, Universidade Católica de Pelotas, Pelotas, 2012.

SIMÕES, Carlos. Curso de Direito do Serviço Social. 7. ed. São Paulo: Cortez Editora, 2014. 592 p. (Vol. 03 da Biblioteca Básica do Serviço Social). ISBN: 9788524921735.

VASCONCELOS, Natalia Batista. Programa Nacional de Assistência Estudantil: uma análise da evolução da assistência estudantil ao longo da história da educação superior no Brasil.

Revista da Católica, Uberlândia, v. 2, n. 3, p. 399-411, 2010. Disponível em:

<http://www.catolicaonline.com.br/revistadacatolica >. Acesso em: 25 Nov. 2016.

\section{${ }^{\mathrm{i}}$ Sobre a autora}

Maria Luciene da Silva Araújo

E-mail: assistente.luciene @ gmail.com / ORCID: http://orcid.org/0000-0002-1509-8587

Universidade do Estado do Rio Grande do Norte - Brasil

Bacharela em Serviço Social pela Universidade do Estado do Rio Grande do Norte [UERN]. 